\title{
Comparison of the mechanisms of heme hydroxylation by heme oxygenases-1 and -2: kinetic and cryoreduction studies
}

\author{
Roman Davydov $^{\dagger}$, Angela S. Fleischhacker ${ }^{\S}$, Ireena Bagai ${ }^{\S} \#$, Brian M. Hoffman ${ }^{\dagger}$, and \\ Stephen W. Ragsdale ${ }^{\S}{ }^{\star}$ \\ †Department of Chemistry, Northwestern University, 2145 Sheridan Road, Evanston, Illinois \\ 60208-3113 \\ §Department of Biological Chemistry, University of Michigan Medical School, Ann Arbor, MI \\ 48109
}

\section{Abstract}

The two isoforms of human heme oxygenase ( $\mathrm{HO} 1$ and $\mathrm{HO} 2)$ catalyze oxidative degradation of heme to biliverdin, $\mathrm{Fe}$, and $\mathrm{CO}$. Unlike $\mathrm{HO} 1, \mathrm{HO} 2$ contains two C-terminal heme regulatory motifs (HRMs) centered at Cys265 and Cys282 that act as redox switches and, in their reduced dithiolate state, bind heme (Fleischhacker, et al., 2015, Biochemistry 54, 2693-708). Here, we describe cryoreduction/annealing and EPR spectroscopic experiments to study the structural features of the oxyheme moiety in $\mathrm{HO} 2$ and to elucidate the initial steps in heme degradation. We conclude that the same mechanism of heme hydroxylation to a-meso-hydroxyheme is employed by both isoforms and that the HRMs do not affect the physico-chemical properties of the oxy$\mathrm{Fe}(\mathrm{II})$ and HOO-Fe(III) states of $\mathrm{HO} 2$. However, the absorption spectrum of oxy-Fe(II)-HO2 is slightly blue shifted relative to that of HO1. Furthermore, heme hydroxylation proceeds three times slower and the oxy-Fe(II) state is 100-fold less stable in HO2 than in HO1. These distinctions are attributed to slight structural variances in the two proteins, including differences in equilibrium between open versus closed conformations. Kinetic studies revealed that heme oxygenation by $\mathrm{HO} 2$ occurs solely at the catalytic core in that a variant of $\mathrm{HO} 2$ lacking the $\mathrm{C}$ terminal HRM domain exhibits the same specific activity as one containing both the catalytic core and HRM domain; furthermore, a truncated variant containing only the HRM region binds but cannot oxidize heme. In summary, $\mathrm{HO} 1$ and $\mathrm{HO} 2$ share similar catalytic mechanisms and the HRMs do not play a direct role in the $\mathrm{HO} 2$ catalytic cycle.

\footnotetext{
*Corresponding Author Stephen W. Ragsdale, Department of Biological Chemistry, University of Michigan Medical School, 1150 W. Medical Center Dr., Ann Arbor, MI 48109-0606. sragsdal@umich.edu, Tel: 734-615-4621, Fax: 734-763-4581.

\#Present Address

(I.B.) Brain and Mind Research Institute, Weill Medical College of Cornell University, New York, NY 1002.

Supporting Information. Includes UV-VIS spectra of Fe(II)-heme HO1 and its complex with $\mathrm{O}_{2}$ and comparison of the EPR spectra of $77 \mathrm{~K}$ cryoreduced oxy HO1 and oxy HO2. (http://pubs.acs.org)

Author Contributions

The manuscript was written through contributions of all authors. All authors have given approval to the final version of the manuscript.

The authors declare no competing financial interests.
} 


\section{Keywords}

Electron Paramagnetic Resonance; Cryoreduction; Oxygenase

Heme oxygenase (HO) catalyzes the $\mathrm{O}_{2}$ - and NADPH-cytochrome $\mathrm{P} 450$ reductasedependent conversion of heme to bilivirdin, free iron, and $\mathrm{CO}$ through three successive oxygenation steps. Heme participates both as a prosthetic group and as substrate in the process. ${ }^{1-4}$ Biliverdin is subsequently converted to the antioxidant bilirubin by biliverdin reductase (BVR). This process is highly important process in metal ion homeostasis, given that both heme and iron are required, yet toxic at elevated levels. The HO/BVR system appears to be the sole mechanism for heme degradation and the sole source of $\mathrm{CO}$ in mammals. In all amniotes (from reptiles and birds to humans), there are two isoforms, HO1 and $\mathrm{HO} 2$, yet most work on the catalytic mechanism has been performed with $\mathrm{HO} 1$. The HO1 catalytic cycle begins with $\mathrm{Fe}(\mathrm{III})$-heme coordination to the neutral imidazole of histidine to form a heme-protein complex (Fe(III)-HO1). ${ }^{1,4-6}$ In the first monooxygenation step, heme is converted to the a-meso-hydroxyheme through the following process. NADPH cytochrome $\mathrm{P} 450$ reductase (CPR) donates one electron to reduce the ferric heme on $\mathrm{HO} 1$ to the ferrous state (Fe(II)-HO1), which promotes the binding of dioxygen to form an oxy$\mathrm{Fe}(\mathrm{II})-\mathrm{HO} 1$ complex. Then, oxy-Fe(II)-HO1 undergoes a second one-electron reduction by CPR to generate hydroperoxyferri-HO. Experiments with meta-chloroperoxybenzoic acid ( $m$-CPBA) and $\mathrm{H}_{2} \mathrm{O}_{2}$ performed by Wilks and Ortiz deMontellano ${ }^{7}$ and Ishikawa ${ }^{2}$ as well as cryoreduction/annealing experiments with oxy-Fe(II)- $\mathrm{HO}^{8}{ }^{8}$ demonstrated that the reactive hydroxylating species for $\mathrm{HO} 1$ is indeed the hydroperoxy ferric $\mathrm{HO}$ species, rather than a high-valent ferryl intermediate, which is the reactive species in most oxidases like peroxidases and cytochrome $\mathrm{P} 450 .{ }^{9}$ In the second oxygenation step, the reactive a-mesohydroxyheme is rapidly and spontaneously autoxidized. Lastly, in the third oxygenation step, $\mathrm{O}_{2}$ is activated by verdoheme, which cleaves the bound porphyrin macrocycle to form biliverdin and free ferrous iron, which dissociate from the protein, preparing the enzyme for the next catalytic cycle. The last step is considered to be the major rate-determining step of HO catalysis.

The two HO isoforms catalyze the same reaction, share $~ 45 \%$ sequence identity and have similar structures of their catalytic cores, which consist of residues 20-248 for HO1 and 1228 for $\mathrm{HO} 2 .{ }^{5,10}$ However, $\mathrm{HO} 1$ and $\mathrm{HO} 2$ differ in several notable ways. $\mathrm{HO} 1$ exhibits inducible expression, whereas $\mathrm{HO} 2$ is expressed constitutively. ${ }^{11} \mathrm{HO} 1$ is localized mainly in the liver and spleen, where it serves to degrade excess heme, whereas $\mathrm{HO} 2$ is present largely in the brain where it is implicated in oxygen sensing by the carotid body, ${ }^{12}, 13$ mediating oxidative stress in neurons ${ }^{14}$ and regulating cerebral blood flow. $5,10,14,15$

A particularly intriguing difference between $\mathrm{HO} 1$ and $\mathrm{HO} 2$ is the complete lack of Cys residues in the former and the presence of three Cys residues as part of heme regulatory motifs (HRMs) in HO2. ${ }^{16-18}$ Spectroscopic and thiol-trapping studies of $\mathrm{HO} 2$ and variants that possess site-directed substitutions in the HRMs provided evidence that the cysteine residues of the two C-terminal HRMs act as a redox switch that interconverts between the disulfide and dithiolate states, and, upon reduction, Cys 265 provides a free thiol group 
capable of coordinating to heme. ${ }^{17,19-21}$ The physiological relevance of this switch was questioned; ${ }^{18}$ however, various studies demonstrated that the redox state of these two HRMs change in accordance with the cellular redox state. ${ }^{17,20}$ Although it was clearly shown that the thiolates can coordinate heme, the role of the HRMs remained unclear. We had conjectured the possibility of a so-called fishhook mechanism, in which one of the Cys thiolates from the HRMs coordinates to the heme bound to the catalytic core ${ }^{17}$ Recently, the oxidized form of $\mathrm{HO} 2\left(\mathrm{HO}_{2}{ }^{\mathrm{O}}\right)$, with its $\mathrm{HRM}$ thiolate ligands tied up in a disulfide bond, was shown to only bind heme at the catalytic core, while $\mathrm{HO}_{2}{ }^{\mathrm{R}}$, the reduced form of $\mathrm{HO}$, containing the HRM Cys residues in the dithiolate state, was shown to bind up to two additional Fe(III)-heme moieties independently of the catalytic core, with an affinity ca. 10fold (HRM1 containing Cys265) and 100-fold (HRM2 containing Cys282) lower, respectively, than that of the catalytic core. ${ }^{22}$ However, it was not clear if the HRM has catalytic activity to degrade its bound Fe(III)-heme.

This report tests for differences in function of $\mathrm{HO} 1$ and $\mathrm{HO} 2$ that might arise because $\mathrm{HO} 1$ has only a single heme binding site, while $\mathrm{HO} 2$ binds additional Fe(III)-heme at the HRMs at its C-terminal end. ${ }^{21,22}$ The role for the HRM in $\mathrm{HO} 2$ has not yet been determined. Because the relatively less studied $\mathrm{HO} 2$ exhibits several modes of binding Fe(III)-heme, including the thiolate/Fe(III)-heme coordination in the HRMs, we had hypothesized that the mechanism of $\mathrm{HO} 2$ catalysis might differ from that of well-characterized HO1. For example, in the proposed fishhook mechanism,,${ }^{17}$ one of the Cys thiolates from the HRMs coordinates to the heme bound to the catalytic core. Recent NMR studies indicate that the Cterminal HRM region of $\mathrm{HO} 2$ does associate in a redox dependent manner with the catalytic core. ${ }^{21}$ Furthermore, although mutagenesis studies demonstrated that the HRMs are not necessary for catalysis at saturating heme concentrations, ${ }^{17}$, the rate limiting step in heme degradation is formation or release of biliverdin; ${ }^{23}$ therefore, it was important to directly examine the spectra of catalytic intermediates to test the possibility that the HRM may be involved in one of the early steps in the mechanism. Finally, given that the role of the HRM is unknown, it was important to determine if there is any heme degradation activity associated with the HRMs or if all of the HO catalytic activity arises from the core.

We now report the combination of radiolytic cryoreduction/annealing with UV-VIS and EPR spectroscopy to study structural features of the oxy-Fe(II)-heme moiety in $\mathrm{HO} 2$ and to elucidate the mechanism of hydroxylation of bound heme, the first step of HO-catalyzed heme degradation. ${ }^{8}$ In general, our combined results suggest that the mechanisms of HO1 and $\mathrm{HO} 2$ are similar; however there are slight differences between the absorption spectra as well as significant differences in the stability of the oxy-Fe(II) states of HO1 and HO2. Furthermore, there is no evidence for a thiol-ligated heme-based intermediate during catalysis and of the three heme-binding sites in $\mathrm{HO} 2$ (the catalytic core and the two HRMs), only the catalytic core can catalyze heme oxidation. 


\section{Methods}

\section{Chemicals}

Sodium dithionite, glycerol, glycer(ol-d3) were bought from Sigma-Aldrich. $\mathrm{D}_{2} \mathrm{O}$ was obtained from Cambridge Isotope Laboratories Inc. $\mathrm{O}_{2}$ was purchased from Cryogenic Gas Co.

\section{Protein Expression and Purification}

The soluble forms of $\mathrm{HO} 2$ were expressed and purified as described previously. ${ }^{21,22}$ Briefly, $\mathrm{HO} 2$ spanning residues 1-288 ( $\left.\mathrm{HO} 2_{\text {sol }}\right)$ or residues 1-248 ( $\left.\mathrm{HO} 2_{\text {core }}\right)$ were expressed with an N-terminal six-His tag from pET28a, purified on a Ni-nitrilotriacetic acid affinity column (Qiagen), and treated with thrombin to remove the affinity tag. $\mathrm{HO} 2$ spanning residues 213-288 ( $\left.\mathrm{HO} 2_{\text {tail }}\right)$ was expressed with $\mathrm{N}$-terminal six-His tag and a protein G B1 (GB1) domain in a modified version of pMCSG7, purified on a Ninitrilotriacetic acid affinity column (Qiagen), and treated with tobacco etch virus protease to remove both the six-His tag and the GB1 domain. After purification and separation from the cleaved affinity tags, all proteins were in the apo form and, additionally, $\mathrm{HO}_{\text {sol }}$ and $\mathrm{HO} 2_{\text {tail }}$ were in the oxidized form with a disulfide bond between Cys265 and Cys282 (here termed $\mathrm{HO} 2_{\text {sol }} \mathrm{O}$ and $\mathrm{HO} 2_{\text {tail }} \mathrm{O}^{\text {). }}$

Oxy-Fe(II)-HO1 ${ }^{3,8}$ and the truncated variant $1-265 \mathrm{HO}^{3,7,8}$ were expressed and purified as described previously.

The soluble form of human cytochrome P450 reductase (CPR) lacking the first 66 amino acids that span the membrane anchor and human biliverdin reductase (BVR) were expressed and purified as described previously. ${ }^{24}$

\section{Preparation of $\mathrm{Fe}(\mathrm{III})-\mathrm{Heme}$ Bound $\mathrm{HO} 2$}

$\mathrm{Fe}$ (III)-heme was freshly prepared in $50 \mathrm{mM}$ Tris buffer (pH 8.0) containing $50 \mathrm{mM} \mathrm{KCl}$ with $15 \%$ dimethyl sulfoxide and $0.1 \mathrm{M} \mathrm{NaOH}$. The concentration was determined by using $\varepsilon_{385}=58.4 \mathrm{mM}^{-1} \mathrm{~cm}^{-1}$ in $0.1 \mathrm{M} \mathrm{NaOH} .{ }^{25}$ As described previously, ${ }^{22}$ excess $\mathrm{Fe}$ (III)-heme was added to $\mathrm{HO} 2_{\text {sol }}{ }^{\mathrm{o}}$ or $\mathrm{HO} 2_{\text {core }}$ and passed through PD-10 desalting columns (GE Healthcare) to remove unbound heme to yield the $\mathrm{Fe}(\mathrm{III})$-heme-bound forms (Fe(III)$\mathrm{HO} 2_{\text {sol }} \mathrm{O}$ and $\mathrm{Fe}(\mathrm{III})-\mathrm{HO} 2_{\text {core }}$, respectively). The $\mathrm{Fe}(\mathrm{III})$-heme-bound forms of the dithiolate forms of $\mathrm{HO} 2_{\text {sol }}$ and $\mathrm{HO} 2_{\text {tail }}\left(\mathrm{Fe}(\mathrm{III})-\mathrm{HO} 2_{\text {sol }} \mathrm{R}\right.$ and $\mathrm{Fe}(\mathrm{III})-\mathrm{HO} 2_{\text {tail }} \mathrm{R}$, respectively) were prepared similarly except under anaerobic conditions with proteins that had been reduced with tris(2-carboxyethyl)phosphine prior to addition of Fe(III)-heme, as described. ${ }^{22}$

Samples of $\mathrm{Fe}(\mathrm{III})-\mathrm{HO} 2_{\text {sol }} \mathrm{O}$ for cryoreduction were prepared as described previously ${ }^{21}$ but with the addition of approximately 1:1 protein: $\mathrm{Fe}(\mathrm{III})$-heme rather than an excess as described above. Thus, the protein used in all cryoreduction conditions contains heme bound only to the catalytic core. 


\section{Oxy-ferrous $\mathrm{HO}_{\text {sol }}{ }^{\mathrm{O}}$ Sample Preparation}

All experiments on cryoreduction were conducted using $0.5 \mathrm{mM}$ oxy-Fe(II)- $\mathrm{HO} 2_{\text {sol }} \mathrm{O}$ in $50 \%$ glycerol (v/v) $-50 \mathrm{mM}$ Tris buffer $\mathrm{pH}$ 8.0. When needed, the protein was exchanged into buffers made using $\mathrm{D}_{2} \mathrm{O}$ and $\mathrm{d}_{3}$-glycerol. $\mathrm{In}_{2} \mathrm{D}_{2} \mathrm{O}$ samples, the $\mathrm{pH}$ was adjusted to $\mathrm{pH}$ 7.6. ${ }^{26}$

The preparation of oxy-ferrous $\mathrm{HO} 2_{\text {sol }} \mathrm{O}$ complex (oxy-Fe(II)-HO2 $2_{\text {sol }}{ }^{\mathrm{O}}$ ) was conducted as follows. The ferrous $\mathrm{HO} 2_{\text {sol }} \mathrm{O}$ samples ( $\mathrm{Fe}(\mathrm{II})-\mathrm{HO} 2_{s o l} \mathrm{O}$ ) were made first by incubating the $\mathrm{Fe}(\mathrm{III})-\mathrm{HO} 2_{\text {sol }} \mathrm{O}$ in aqueous buffer in an anaerobic glovebox overnight at $3{ }^{\circ} \mathrm{C}$ to remove oxygen from the protein solution. An aliquot of a standardized solution of sodium dithionite was added to reduce $\mathrm{Fe}(\mathrm{III})-\mathrm{HO} 2_{\text {sol }} \mathrm{O}$ to $\mathrm{Fe}(\mathrm{II})-\mathrm{HO} 2_{\text {sol }} \mathrm{O}$, using $10 \%$ excess of dithionite. An extinction coefficient of $8000 \mathrm{M}^{-1} \mathrm{~cm}^{-1}$ at $315 \mathrm{~nm}$ was used to determine the concentration of dithionite. Then, the reduced protein solution was mixed with oxygen-free glycerol. Complete reduction of the protein was confirmed spectrophotometrically. The sample of $\mathrm{Fe}(\mathrm{II})-\mathrm{HO} 2_{\text {sol }} \mathrm{O}$ was transferred into EPR tubes. $\mathrm{Oxy}-\mathrm{Fe}(\mathrm{II})-\mathrm{HO} 2_{\text {sol }} \mathrm{O}$ complexes were made by bubbling the $\mathrm{Fe}(\mathrm{II})-\mathrm{HO} 2_{\text {sol }} \mathrm{O}$ sample at $-25^{\circ} \mathrm{C}$ with $20 \mathrm{ml}$ cold oxygen gas for $40-60 \mathrm{~s}$. The samples were then stored in quartz EPR tubes at $77 \mathrm{~K}$ until cryoreduction.

$\gamma$-Irradiation of the frozen hemoprotein solutions at $77 \mathrm{~K}$ typically was performed for $20 \mathrm{~h}$ (dose rate of $0.1 \mathrm{Mrad} / \mathrm{h}$, total dose $2 \mathrm{Mrad}$ ) using a Gammacell $220{ }^{60} \mathrm{Co}$. Annealing at temperatures over the range $77-270 \mathrm{~K}$ was performed by placing the EPR sample in the appropriate bath (e.g., $n$-pentane or methanol cooled with liquid nitrogen) and then refreezing in liquid nitrogen.

\section{Spectroscopic Techniques}

X-band CW EPR spectra were recorded on a Bruker ESP 300 spectrometer equipped with an Oxford Instruments ESR 910 continuous He flow cryostat. As shown previously, $\gamma$ irradiation at $77 \mathrm{~K}$ yields an intense EPR signal at $\mathrm{g}=2.0$ from radiolytically generated organic radicals; such signals are truncated in the reported spectra for clarity.

UV-Visible spectra at $77 \mathrm{~K}$ were acquired directly on the EPR samples, which were in $4 \mathrm{~mm}$ (outer diameter) quartz tubes that were immersed in a liquid nitrogen-filled "finger dewar" placed in the cuvette-holder of a USB 2000 spectrophotometer (Ocean Optics, Inc.).

\section{Steady-state activity assays with $\mathrm{Fe}(\mathrm{III})-\mathrm{HO} 2$}

With minor modifications of the assay described previously, ${ }^{24} \mathrm{HO} 2$ was assayed in a $200 \mu \mathrm{L}$ reaction containing $0.1 \mu \mathrm{M}$ Fe(III)-HO2, $15 \mu \mathrm{M} \mathrm{Fe(III)-heme,} 0.35 \mu \mathrm{M}$ BVR, $0.25 \mu \mathrm{g} / \mu \mathrm{L}$ BSA, $20 \mathrm{U} / \mu \mathrm{L}$ catalase, and $5 \mu \mathrm{M} \mathrm{CPR}$. After a 2 min incubation at $37{ }^{\circ} \mathrm{C}$, the reaction was initiated with the addition of $2 \mu \mathrm{L}$ of $100 \mathrm{mM}$ NADPH and monitored spectrophotometrically at $468 \mathrm{~nm}$. The activity was calculated using a difference extinction coefficient of $43 \mathrm{mM}^{-1} \mathrm{~cm}^{-1}$ between Fe(III)-heme and the product, bilirubin. 


\section{Results and Discussion}

\section{Absorption spectra of $\mathrm{Fe}(\mathrm{II})-\mathrm{HO}{ }_{\text {sol }} \mathrm{O}$ and its complex with $\mathrm{O}_{2}$}

The absorption spectra of $\mathrm{Fe}(\mathrm{II})-\mathrm{HO} 2_{\text {sol }} \mathrm{O}$ and its $\mathrm{O}_{2}$ complex are presented in Figure 1. The spectrum of $\mathrm{Fe}(\mathrm{II})-\mathrm{HO} 2_{\text {sol }} \mathrm{O}$ at room temperature shows poorly resolved $\mathrm{\alpha}$ - and $\beta$-bands at $\sim 530$ and $558 \mathrm{~nm}$ and a broad Soret band at $430 \mathrm{~nm}$ (not shown) that is similar to that reported previously. ${ }^{17,19}$ The observed spectrum resembles that of the high-spin, fivecoordinate $\mathrm{Fe}(\mathrm{II})$-heme $\mathrm{HO} 1$ complex. ${ }^{27}$ However, as shown previously, ${ }^{19}$ in the low temperature spectrum of $\mathrm{Fe}(\mathrm{II})-\mathrm{HO} 2_{\text {sol }} \mathrm{O}$ (Figure 1), two Soret bands can be resolved and the $a$ - and $\beta$-bands are more distinct. ${ }^{19}$ To our knowledge, the observed temperature effect does not occur for $\mathrm{Fe}(\mathrm{II})$-HO1 (Figure S1) nor for any other studied high-spin pentacoordinate ferrous hemoprotein. Rather, the temperature effect observed for $\mathrm{Fe}(\mathrm{II})-\mathrm{HO} 2_{s o l} \mathrm{O}$ has previously been suggested to be due to the formation of a low-spin hexacoordinate $\mathrm{Fe}(\mathrm{II})$ $\mathrm{HO} 2_{\text {sol }}{ }^{\mathrm{O}}$ species at low temperatures. ${ }^{19}$ However, the identity of the sixth ligand (besides His and the tetrapyrrole nitrogens) in low-spin $\mathrm{Fe}(\mathrm{II})-\mathrm{HO} 2_{\text {sol }} \mathrm{O}$ remains uncertain. While one of the Cys residues in the two HRMs was considered to be a candidate based on the speculation (described above) that Cys may act as a ligand to Fe(III)-heme bound to the core, ${ }^{17}$ it now appears that this is not so, as the same hexacoordinate Fe(II)-heme species was observed with a variant containing substitutions at the HRM Cys residues. ${ }^{22}$ An obvious second possibility is a water molecule. ${ }^{28}$

Addition of $\mathrm{O}_{2}$ to $\mathrm{Fe}(\mathrm{II})-\mathrm{HO} 2_{\text {sol }} \mathrm{O}$ at $-25{ }^{\circ} \mathrm{C}$ results in the appearance of a new absorption spectrum (Figure 1) with peaks at $536 \mathrm{~nm}$ and $572 \mathrm{~nm}$ that can be assigned to the dioxygen adduct of the $\mathrm{Fe}$ (II)-heme of $\mathrm{HO} 2$, termed oxy-Fe(II)-HO2 ${ }_{\text {sol }} \mathrm{O}$. The absorption spectrum of the oxy adduct is slightly $(2-3 \mathrm{~nm}$ ) blue shifted relative to that for oxy-Fe(II)-HO1 (Figure $\mathrm{S} 2)$. The observed species is unstable at room temperature and rapidly $\left(\mathrm{t}_{1 / 2} \sim 1.5 \mathrm{~min}\right)$ converts into ferriheme $\mathrm{HO} 2$ with a rate constant that is approximately 100 -fold faster than that for oxy-Fe(II)-HO1 (t $\mathrm{t}_{1 / 2} \sim$ several hours). ${ }^{8}$

Thus, the differences in the UV-visible spectra of the Fe(II)- and oxy-Fe(II)- states of HO1 and $\mathrm{HO} 2$ and the marked instability of the oxy-Fe(II) state of $\mathrm{HO} 2$ relative to that of oxy$\mathrm{Fe}(\mathrm{II})-\mathrm{HO} 1$ indicate that there are functionally significant differences between these states that may reflect the small differences in the crystal structures of the catalytic cores of these proteins, which appear to be restricted to the proximal and distal helices that directly interact with the heme. ${ }^{10}$ In addition, $\mathrm{HO} 2$ appears to more favor the open conformation than HO1. These differences also may relate to the influence of the 20 additional $\mathrm{N}$-terminal residues of $\mathrm{HO} 2$ or the C-terminal HRM domain, neither of which were observed in the $\mathrm{HO} 2$ crystal structure and both of which are conformationally mobile regions. ${ }^{21}$ Indeed, NMR studies indicated a redoxdependent interaction between the $\mathrm{HO} 2$ catalytic core and its $\mathrm{C}$-terminal HRM region. ${ }^{21}$

\section{EPR spectroscopy of cryoreduced oxy-Fe(II)-HO2}

After radiolytic cryoreduction at $77 \mathrm{~K}$, oxy-Fe(II)-HO2 shows a rhombic EPR spectrum with $\mathbf{g}=[2.38,2.19,1.93]$ (Figure 2), which is very similar to that reported for cryoreduced oxy$\mathrm{Fe}(\mathrm{II})-\mathrm{HO} 1$, i.e., $\mathbf{g}=[2.37,2.19,1.93]$ (Figure $\mathrm{S} 2$ ) and has been assigned to the hydroperoxy 
ferric intermediate. ${ }^{8,} 29$ Such a primary product of cryoreduction as that of oxy-Fe(II)-HO2 trapped at $77 \mathrm{~K}$ retains the conformation of the parent dioxygen complex, which often differs from that of the equilibrium state of the cyroreduced species. The EPR spectra presented in Fig.2 imply that oxy-Fe(II)-HO2 exhibits a single conformer of the parent Fe-O-O moiety. The spectroscopic equivalence of the cryoreduced oxy complexes of HO1 and HO2 suggests that there is significant structural similarity between the distal environments of the hydroperoxy-heme moiety in the two isoforms. As with HO1, the EPR signal of the cryogenerated hydroperoxy intermediate of $\mathrm{HO} 2$ is characterized by higher rhombicity than that of other studied hemoproteins, including globins, ${ }^{30,} 31$ cytochromes P450, ${ }^{32-35}$ peroxidases; $; 6,37$ and nitric oxide synthase (NOS). ${ }^{38}$ The results may be the consequence of unusual geometric/H-bonding constraints in the distal heme environment to promote the formation of a $\mathrm{Fe}-\mathrm{OOH}$ bond, which is the catalytically active species that hydroxylates the heme in $\mathrm{HO} 1$ and $\mathrm{HO} 2 .{ }^{4,}{ }^{39}$ It was noted that $\mathrm{HO} 1$ exhibits an unusually acute $\mathrm{Fe}-\mathrm{O}-\mathrm{OH}$ angle, which provides van der Waals contact between the terminal oxygen of the ferrichydroperoxide and the a-meso carbon. ${ }^{4}$ The similarity of the EPR spectra of cryoreduced oxy-Fe(II)-HO2 to that of oxy-Fe(II)-HO1 suggests that the ferric-hydroperoxide intermediate in $\mathrm{HO} 2$ enforces a similar geometry to promote the heme ring hydroxylation.

Because cryoreduction of the diamagnetic oxy-Fe(II)-HO2 complex at $77 \mathrm{~K}$ generates an EPR-active state that retains the conformation of the oxy precursor, $32,35,40,41$ this procedure generates a sensitive EPR probe of the diamagnetic precursor. In situ cryoreduction of oxy-Fe(II)-heme first forms the peroxo-ferriheme species, which must then undergo proton transfer at $77 \mathrm{~K}$ to form the observed hydroperoxy-ferric state. Previous cryoreduction studies with a variety of oxy-hemoproteins, including cytochrome $\mathrm{P} 450,{ }^{32}$ NOS, ${ }^{38}$ oxy globins, ${ }^{30,31}$ peroxidases $^{36,37}$ and $\mathrm{HO}^{8}$ showed that the observation of proton transfer to the basic peroxo heme ligand trapped at $77 \mathrm{~K}$ or below implies the existence of a hydrogen-bonded proton delivery network that includes an ordered active-site water molecule that is hydrogen bonded to the terminal oxygen atom. Observation of the hydroperoxy ferriheme as the product of $77 \mathrm{~K}$ cryoreduction of oxy-Fe(II)-HO2 implies the presence of such a network, which was shown to promote very efficient proton transfer to the cryogenerated peroxy ligand in $\mathrm{HO} 1$ even at helium temperatures. ${ }^{29}$ The transferred proton can originate either from acid/base groups provided by amino acid residues within the active site,, 32 from bound substrate ${ }^{38,39}$ or from water clusters connected to the active site. ${ }^{42}$ The X-ray crystal structure of $\mathrm{HmuO}$, which is structurally similar to that of $\mathrm{HO} 1$ and $\mathrm{HO} 2$, in its oxy complex showed the terminal oxygen atom of the peroxo ligand interacting with a water molecule as part of a hydrogen-bonding network containing a water cluster and a catalytically critical distal Asp residue. ${ }^{43}$ Site-specific substitution of the analogous distal Asp140 in HO1 to Ala inhibits proton delivery and consequently the conversion of cryogenerated peroxo to the hydroperoxo species. ${ }^{8}$

These cryoreduction and EPR spectroscopic studies of the cryoreduced oxy complex of HO2 show its significant similarity to $\mathrm{HO1}$, and strongly suggest that the distal environments of the hydroperoxy-heme moiety in the two isoforms are highly similar, with a very effective H-bonding pathway for rapid proton delivery to the peroxo-ferriheme species. Furthermore, 
the results indicate that, like $\mathrm{HO} 1$, the hydroperoxide state exhibits an unusual geometry that is poised for heme ring hydroxylation.

\section{Annealing of cryoreduced oxy-Fe(II)-HO2}

EPR spectroscopy shows that during annealing of cryoreduced oxy-Fe(II)-HO2 at progressively higher temperatures (Figure 2) the trapped hydroperoxy-heme state relaxes to other such states. Annealing at temperatures between $145-175 \mathrm{~K}$ produced a negligible shift in the $\mathrm{g}_{1}$ feature, from 2.38 to 2.39 . However, upon annealing at $185 \mathrm{~K}$ for $2 \mathrm{~min}$, the $\mathrm{g}_{1}$ feature showed asymmetric broadening to lower field. Further, annealing at $200 \mathrm{~K}$ converts some of the $\mathrm{g}_{1}=2.39$ state to a relaxed hydroperoxoferri conformer with $\mathrm{g}_{1}=2.36$, but no noticeable changes of $\mathrm{g}_{2}$ or $\mathrm{g}_{3}$. A similar relaxation has been observed with cryoreduced oxy-Fe(II)-HO1. ${ }^{8}$

The relaxation to two spectroscopically similar equilibrium hydroperoxo-forms, $\mathrm{g}_{1}=2.36$ and 2.39, which are likely in equilibrium, presumably involves rearrangement of the distal pocket, the putative water network, and possibly the protein side chains. After the presumed rearrangement, the equilibrium hydroperoxo-ferric intermediates of $\mathrm{HO} 2$ are prepared for the actual tetrapyrrole hydroxylation step. During annealing at $215 \mathrm{~K}$, both hydroperoxy intermediates decay (Figure 2) and their disappearance is accompanied by the formation of a new rhombic high spin signal with $\mathrm{g}_{\mathrm{x}}=6.1$ and $\mathrm{g}_{\mathrm{y}}=5.72$, characteristic of the a-mesohydroxyheme product (Figure 3). 8,44

Decay of the hydroperoxy intermediates of $\mathrm{HO} 2$ to form the a-meso-hydroxyheme exhibits a notable solvent kinetic isotope effect of $~ 3.1(210 \mathrm{~K})$ (Figure 4 ), as reported for HO1, ${ }^{45}$ which indicates that for both isoforms, protonation of the hydroperoxy ligand is the rate limiting hydroxylation step at this temperature. Figure 5 shows that at $210 \mathrm{~K}$ the hydroxylation of heme by $\mathrm{HO} 1$ proceeds $\sim 3$ times faster than that of $\mathrm{HO} 2$.

Although Cys 265 and Cys 282 are present in their reduced states and potentially available to bind heme, we saw no evidence for any thiolate-ligated heme species at any step in the HO2 catalytic cycle. In fact, all of the spectral intermediates described so far exhibit EPR spectral features that are similar to those that have been previously observed for HO1. Even the kinetic isotope effect of 3.1 observed here for decay of the ferric hydroperoxy intermediates of $\mathrm{HO} 2$ is similar to that for HO1. These results indicate that the HRMs do not play a direct role in conversion of ferric hydroperoxy intermediate to a-meso-hydroxyheme. However, there are differences among the rates of the various conversion steps, which reflect structural differences in the active sites of $\mathrm{HO} 1$ and $\mathrm{HO} 2$ and/or the influence of the HRMs.

\section{Steady-state activity of $\mathrm{Fe}(\mathrm{III})-\mathrm{HO} 2$}

Previous studies have indicated that the HRMs are not necessary for catalysis at saturating heme concentrations ${ }^{16}$ and studies described above suggest that the HRMs do not ligate to heme at any of the steps in the catalytic cycle. We performed steady state assays with $\mathrm{Fe}(\mathrm{III})$-heme-bound proteins in which the HRMs were either not present $\left(\mathrm{HO}_{2}\right.$ core $)$ or reduced $\left(\mathrm{HO} 2_{\text {tail }}\right.$ and $\left.\mathrm{HO} 2_{\text {sol }} \mathrm{R}\right)$, since, in the oxidized state, the disulfides are not available to participate in turnover. $\mathrm{Fe}(\mathrm{III})-\mathrm{HO} 2_{\text {tail }}$, which contains two bound hemes and spans only 
the C-terminal HRM region but lacks the catalytic core, has no detectable activity. Further, there was no difference in activity amongst $\mathrm{Fe}(\mathrm{III})-\mathrm{HO} 2_{\text {core }}(443 \pm 13 \mathrm{nmol} / \mathrm{min} / \mathrm{mg}$ ), which contains a single heme bound to the core and lacks the HRM region; $\mathrm{Fe}(\mathrm{III})-\mathrm{HO} 2_{\text {sol }} \mathrm{O}(388 \pm$ $14 \mathrm{nmol} / \mathrm{min} / \mathrm{mg}$ ), which also contains a single heme because the HRMs are oxidized; and $\mathrm{Fe}(\mathrm{III})-\mathrm{HO} 2_{\text {sol }}^{\mathrm{R}}(377 \pm 28 \mathrm{nmol} / \mathrm{min} / \mathrm{mg})$, which contains heme bound both to the core and the HRMs.

Therefore, the combined kinetic and spectroscopic results clearly demonstrate that all heme oxidation activity comes from the $\mathrm{HO} 2$ catalytic core, consisting of residues 1-248. Given the structural homology between $\mathrm{HO} 1$ and $\mathrm{HO} 2$, we suggest that the catalytic activity of $\mathrm{HO} 2$ derives from highly conserved residues $21-248$ of HO2. Furthermore, residues 213288 from the C-terminal HRM region, containing a highly divergent sequence relative to that of HO1, and is not directly involved in the mechanism of heme turnover. The steadystate kinetic results are consistent with the cryoreduction studies, which showed that the mechanisms of $\mathrm{HO} 1$ and $\mathrm{HO} 2$ are the same.

\section{Conclusion}

This report tests for differences in function of $\mathrm{HO} 1$ and $\mathrm{HO} 2$ that might arise because $\mathrm{HO} 1$ binds a single heme within its catalytic core, while $\mathrm{HO} 2$ binds additional Fe(III)-heme at the HRMs at its C-terminal tail. ${ }^{21,22}$ Cryoreduction and spectroscopic experiments, which allow trapping of early intermediates in the catalytic cycle, reveal that the distal environments of the oxy heme centers in $\mathrm{HO} 1$ and $\mathrm{HO} 2$ as well as the catalytically active hydroperoxo intermediates of the two proteins are very similar. Thus, it is clear that heme hydroxylation by $\mathrm{HO} 2$ operates through the same intermediates as HO1. On the other hand, the oxy-Fe(II)states of $\mathrm{HO} 2$ and $\mathrm{HO} 1$ display notable differences in their absorption spectra as well as differences in the rates at which early intermediates interconvert. For example, oxy-Fe(II)$\mathrm{HO} 2$ is significantly less stable than oxy-Fe(II)-HO1, converting into ferri-heme $\mathrm{HO} 2$ approximately 100-fold faster than oxy-Fe(II)-HO1. Furthermore, heme hydroxylation by HO1 proceeds $\sim 3$ times faster than that by HO2. These kinetic differences are suggested to relate to the small differences between $\mathrm{HO} 1$ and $\mathrm{HO} 2$ in the conformations of the proximal and distal helices that interact with the heme and/or the equilibrium between the open and closed conformations of the catalytic core, with $\mathrm{HO} 2$ more favoring the open conformation than $\mathrm{HO} 1 .^{10}$ Our results strongly indicate that the HRMs are not involved in thiol ligation to the catalytic heme in any of the observed catalytic intermediates and that the HRMs have no HO activity.

\section{Supplementary Material}

Refer to Web version on PubMed Central for supplementary material.

\section{Acknowledgments}

\section{FUNDING SOURCES}

Support was provided by NIH grants R01-HL-102662A (SWR) from the National Heart, Lung and Blood Institute and R01-GM 111097 (BMH) from the National Institute for General Medical Sciences. We thank Prof. H. Halpern, Pritzker School of Medicine, University of Chicago, for access to the ${ }^{60}$ Co Gammacell irradiator. 


\section{ABBREVIATIONS}

$\begin{array}{ll}\text { EPR } & \text { Electron Paramagnetic Resonance } \\ \text { HO } & \text { heme oxygenase } \\ \text { m-CPBA } & \text { meta-chloroperoxybenzoic acid } \\ \text { HRM } & \text { heme regulatory motif } \\ \text { CPR } & \text { cytochrome P450 reductase } \\ \text { BVR } & \text { biliverdin reductase }\end{array}$

\section{References}

1. Ortiz de Montellano P. Heme oxygenase mechanism: Evidence for an electrophilic, ferric peroxide species. Acc. Chem. Res. 1998; 31:543-549.

2. Ishikawa K, Takeuchi N, Takahashi S, Matera KM, Sato M, Shibahara S, Rousseau DL, Ikeda-Saito M, Yoshida T. Heme oxygenase-2. Properties of the heme complex of the purified tryptic fragment of recombinant human heme oxygenase-2. J. Biol. Chem. 1995; 270:6345-6350. [PubMed: 7890772]

3. Migita CT, Matera KM, Ikeda-Saito M, Olson JS, Fujii H, Yoshimura T, Zhou H, Yoshida T. The oxygen and carbon monoxide reactions of heme oxygenase. J. Biol. Chem. 1998; 273:945-949. [PubMed: 9422754]

4. Matsui T, Iwasaki M, Sugiyama R, Unno M, Ikeda-Saito M. Dioxygen activation for the selfdegradation of heme: reaction mechanism and regulation of heme oxygenase. Inorg. Chem. 2010; 49:3602-3609. [PubMed: 20380462]

5. Schuller DJ, Wilks A, Ortiz de Montellano PR, Poulos TL. Crystal structure of human heme oxygenase-1. Nat. Struct. Biol. 1999; 6:860-867. [PubMed: 10467099]

6. Lad L, Schuller DJ, Shimizu H, Friedman J, Li H, Ortiz de Montellano PR, Poulos TL. Comparison of the heme-free and -bound crystal structures of human heme oxygenase-1. J. Biol. Chem. 2003; 278:7834-7843. [PubMed: 12500973]

7. Wilks A, Ortiz de Montellano PR. Rat liver heme oxygenase. High level expression of a truncated soluble form and nature of the meso-hydroxylating species. J. Biol. Chem. 1993; 268:22357-22362. [PubMed: 8226746]

8. Davydov R, Kofman V, Fujii H, Yoshida T, Ikeda-Saito M, Hoffman BM. Catalytic mechanism of heme oxygenase through EPR and ENDOR of cryoreduced oxy-heme oxygenase and its Asp 140 mutants. J. Am. Chem. Soc. 2002; 124:1798-1808. [PubMed: 11853459]

9. Sono M, Roach MP, Coulter ED, Dawson JH. Heme-Containing Oxygenases. Chem. Rev. 1996; 96:2841. [PubMed: 11848843]

10. Bianchetti CM, Li Y, Ragsdale SW, Phillips GN Jr. Comparison of Apo and Heme-bound Crystal Structures of a Truncated Human Heme Oxygenase-2. J. Biol. Chem. 2007; 282:37624-37631. [PubMed: 17965015]

11. Maines MD. The heme oxygenase system: a regulator of second messenger gases. Annu. Rev. Pharmacol. Toxicol. 1997; 37:517-554. [PubMed: 9131263]

12. Williams SE, Wootton P, Mason HS, Bould J, Iles DE, Riccardi D, Peers C, Kemp PJ. Hemoxygenase-2 is an oxygen sensor for a calcium-sensitive potassium channel. Science. 2004; 306:2093-2097. [PubMed: 15528406]

13. Hoshi T, Lahiri S. Cell biology. Oxygen sensing: it's a gas! Science. 2004; 306:2050-2051. [PubMed: 15604396]

14. Regan RF, Chen J, Benvenisti-Zarom L. Heme oxygenase-2 gene deletion attenuates oxidative stress in neurons exposed to extracellular hemin. BMC Neurosci. 2004; 5:34. [PubMed: 15377391] 
15. Galbraith R. Heme oxygenase: who needs it? Proc Soc Exp Biol Med. 1999; 222:299-305. [PubMed: 10601889]

16. McCoubrey WK Jr, Huang TJ, Maines MD. Heme oxygenase-2 is a hemoprotein and binds heme through heme regulatory motifs that are not involved in heme catalysis. J. Biol. Chem. 1997; 272:12568-12574. [PubMed: 9139709]

17. Yi L, Ragsdale SW. Evidence that the heme regulatory motifs in heme oxygenase-2 serve as a thiol/disulfide redox switch regulating heme binding. J. Biol. Chem. 2007; 282:20156-21067.

18. Varfaj F, Lampe JN, Ortiz de Montellano PR. Role of Cysteine Residues in Heme Binding to Human Heme Oxygenase-2 Elucidated by Two-dimensional NMR Spectroscopy. J. Biol. Chem. 2012; 287:35181-35191. [PubMed: 22923613]

19. Gardner JD, Yi L, Ragsdale SW, Brunold TC. Spectroscopic Insights into Axial Ligation and Active-site H-bonding in Substrate-Bound Human Heme Oxygenase-2. J. Biol. Inorg. Chem. 2010; 15:1117-1127. [PubMed: 20502928]

20. Yi L, Jenkins PM, Leichert LI, Jakob U, Martens JR, Ragsdale SW. The heme regulatory motifs in heme oxygenase-2 form a thiol/disulfide redox switch that responds to the cellular redox state. J. Biol. Chem. 2009; 284:20556-20561. [PubMed: 19473966]

21. Bagai I, Sarangi R, Fleischhacker A, Sharma A, Hoffman B, Zuiderweg E, Ragsdale S. Spectroscopic studies reveal that the heme regulatory motifs of heme oxygenase- 2 are dynamically disordered and exhibit redox-dependent interaction with heme. Biochemistry. 2015; 54:26932708. [PubMed: 25849895]

22. Fleischhacker AS, Sharma A, Choi M, Spencer AM, Bagai I, Hoffman BM, Ragsdale SW. The Cterminal heme regulatory motifs of heme oxygenase-2 are redox-regulated heme binding sites. Biochemistry. 2015; 54:2709-2718. [PubMed: 25853617]

23. Liu Y, Ortiz de Montellano PR. Reaction intermediates and single turnover rate constants for the oxidation of heme by human heme oxygenase-1. J. Biol. Chem. 2000; 275:5297-5307. [PubMed: 10681502]

24. Spencer AM, Bagai I, Becker DF, Zuiderweg ER, Ragsdale SW. Protein-Protein Interactions in the Mammalian Heme Degradation Pathway: Heme Oxygenase-2, Cytochrome P450 Reductase and Biliverdin Reductase. J. Biol. Chem. 2014; 289:29836-29858. [PubMed: 25196843]

25. Dawson, RMC. Data for biochemical research. 3rd. Oxford: Clarendon Press, New York, NY; 1986.

26. Glasoe PK, Long FA. Use of glass electrodes to measure acidities in deuterium oxide. J. Phys. Chem. 1960; 64:188-190.

27. Sun J, Wilks A, Ortiz de Montellano PR, Loehr TM. Resonance Raman and EPR spectroscopic studies on heme-heme oxygenase complexes. Biochemistry. 1993; 32:14151-14157. [PubMed: 8260499]

28. Beitlich T, Kuhnel K, Schulze-Briese C, Shoeman RL, Schlichting I. Cryoradiolytic reduction of crystalline heme proteins: analysis by UV-Vis spectroscopy and X-ray crystallography. J. Synchrotron Radiat. 2007; 14:11-23. [PubMed: 17211068]

29. Davydov R, Chemerisov S, Werst DE, Rajh T, Matsui T, Ikeda-Saito M, Hoffman BM. Proton transfer at helium temperatures during dioxygen activation by heme monooxygenases. J. Am. Chem. Soc. 2004; 126:15960-15961. [PubMed: 15584719]

30. Davydov RM, Yoshida T, Ikeda-Saito M, Hoffman BM. Hydroperoxy-Heme Oxygenase Generated by Cryoreduction Catalyzes the Formation of a-meso-Hydroxyheme as Detected by EPR and ENDOR. J. Am. Chem. Soc. 1999; 121:10656-10657.

31. Kappl R, Hohn-Berlage M, Huttermann J, Bartlett N, Symons MCR. Electron-Spin and Electron Nuclear Double-Resonance of the [FeO2]-center from irradiated oxyhemoglobin and oxymyoglobin. Biochim Biophys Acta. 1985; 827:327-343.

32. Davydov R, Makris TM, Kofman V, Werst DE, Sligar SG, Hoffman BM. Hydroxylation of camphor by reduced oxy-cytochrome P450cam: mechanistic implications of EPR and ENDOR studies of catalytic intermediates in native and mutant enzymes. J. Am. Chem. Soc. 2001; 123:1403-1415. [PubMed: 11456714] 
33. Davydov R, Razeghifard R, Im SC, Waskell L, Hoffman BM. Characterization of the microsomal cytochrome $\mathrm{P} 450$ 2B4 O2 activation intermediates by cryoreduction and electron paramagnetic resonance. Biochemistry. 2008; 47:9661-9666. [PubMed: 18700729]

34. Davydov R, Gilep AA, Strushkevich NV, Usanov SA, Hoffman BM. Compound I is the reactive intermediate in the first monooxygenation step during conversion of cholesterol to pregnenolone by cytochrome P450scc: EPR/ENDOR/cryoreduction/annealing studies. J. Am. Chem. Soc. 2012; 134:17149-17156. [PubMed: 23039857]

35. Davydov R, Hoffman BM. Active intermediates in heme monooxygenase reactions as revealed by cryoreduction/annealing, EPR/ENDOR studies. Arch. Biochem. Biophys. 2011; 507:36-43. [PubMed: 20854788]

36. Davydov R, Osborne RL, Shanmugam M, Du J, Dawson JH, Hoffman BM. Probing the oxyferrous and catalytically active ferryl states of Amphitrite ornata dehaloperoxidase by cryoreduction and EPR/ENDOR spectroscopy. Detection of compound I. J. Am. Chem. Soc. 2010; 132:1499515004. [PubMed: 20925340]

37. Denisov IG, Makris TM, Sligar SG. Formation and decay of hydroperoxo-ferric heme complex in horseradish peroxidase studied by cryoradiolysis. J. Biol. Chem. 2002; 277:42706-42710. [PubMed: 12215454]

38. Davydov R, Sudhamsu J, Lees NS, Crane BR, Hoffman BM. EPR and ENDOR characterization of the reactive intermediates in the generation of NO by cryoreduced oxy-nitric oxide synthase from Geobacillus stearothermophilus. J. Am. Chem. Soc. 2009; 131:14493-14507. [PubMed: 19754116]

39. Rivera M, Zeng Y. Heme oxygenase, steering dioxygen activation toward heme hydroxylation. J. Inorg. Biochem. 2005; 99:337-354. [PubMed: 15598511]

40. Davydov R, Kofman V, Nocek JM, Noble RW, Hui H, Hoffman BM. Conformational substates of the oxyheme centers in alpha and beta subunits of hemoglobin as disclosed by EPR and ENDOR studies of cryoreduced protein. Biochemistry. 2004; 43:6330-6338. [PubMed: 15147217]

41. Davydov RM, Chauhan N, Thackray SJ, Anderson JL, Papadopoulou ND, Mowat CG, Chapman SK, Raven EL, Hoffman BM. Probing the ternary complexes of indoleamine and tryptophan 2,3dioxygenases by cryoreduction EPR and ENDOR spectroscopy. J. Am. Chem. Soc. 2010; 132:5494-5500. [PubMed: 20353179]

42. Guallar V, Harris DL, Batista VS, Miller WH. Proton-transfer dynamics in the activation of cytochrome P450eryF. J. Am. Chem. Soc. 2002; 124:1430-1437. [PubMed: 11841312]

43. Matsui T, Unno M, Ikeda-Saito M. Heme oxygenase reveals its strategy for catalyzing three successive oxygenation reactions. Acc. Chem. Res. 2010; 43:240-247. [PubMed: 19827796]

44. Liu Y, Moenne-Loccoz P, Loehr TM, Ortiz de Montellano PR. Heme oxygenase-1, intermediates in verdoheme formation and the requirement for reduction equivalents. J. Biol. Chem. 1997; 272:6909-6917. [PubMed: 9054378]

45. Davydov R, Matsui T, Fujii H, Ikeda-Saito M, Hoffman BM. Kinetic isotope effects on the ratelimiting step of heme oxygenase catalysis indicate concerted proton transfer/heme hydroxylation. J. Am. Chem. Soc. 2003; 125:16208-16209. [PubMed: 14692760] 


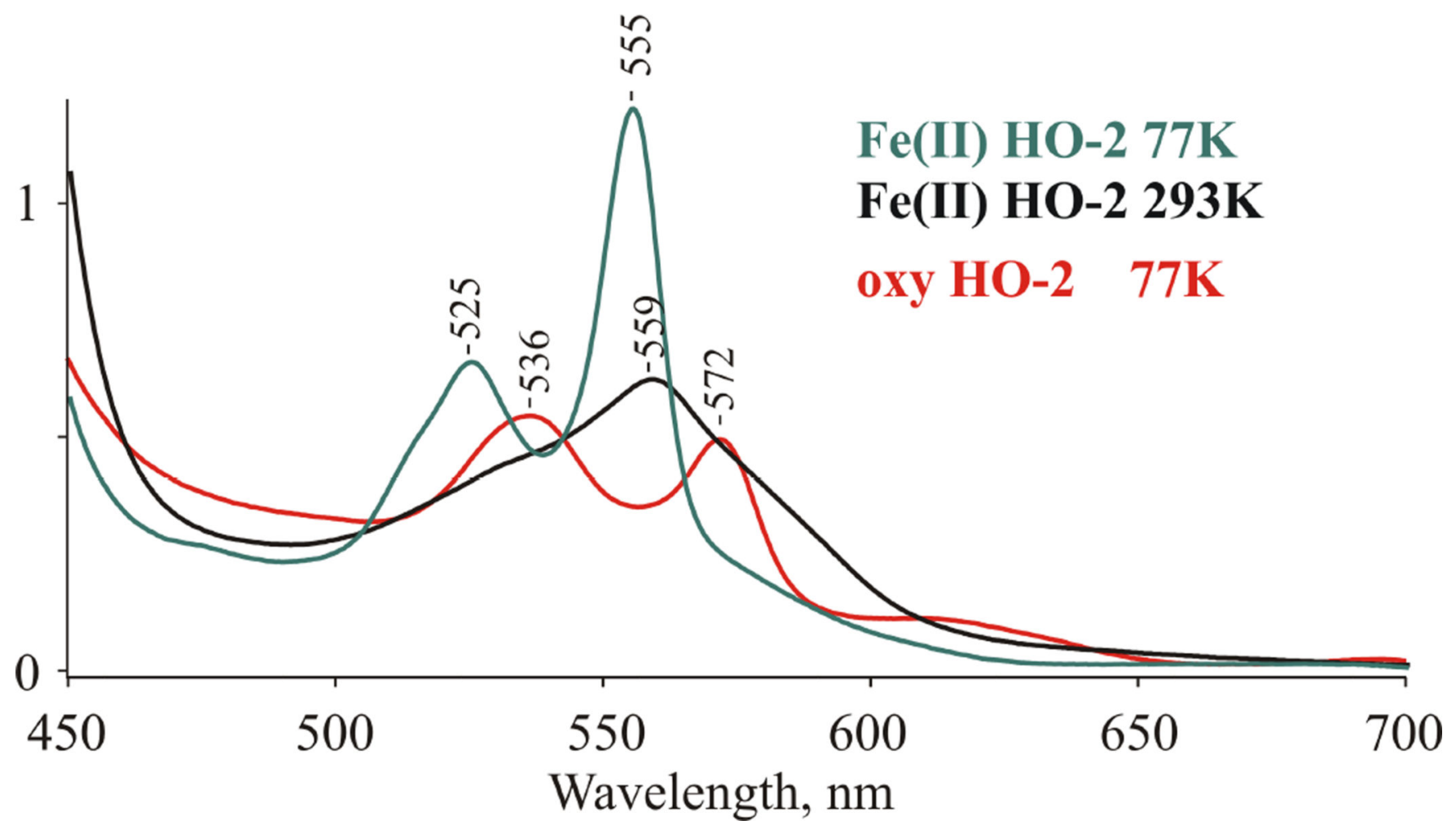

Figure 1.

Absorption spectra of ferrous $\mathrm{HO} 2$ in $50 \%$ glycerol/buffer ( $\mathrm{pH}$ 8.2) measured at room temperature (black) and at $77 \mathrm{~K}$ (green) and of its dioxygen adduct (red) measured at $77 \mathrm{~K}$. 


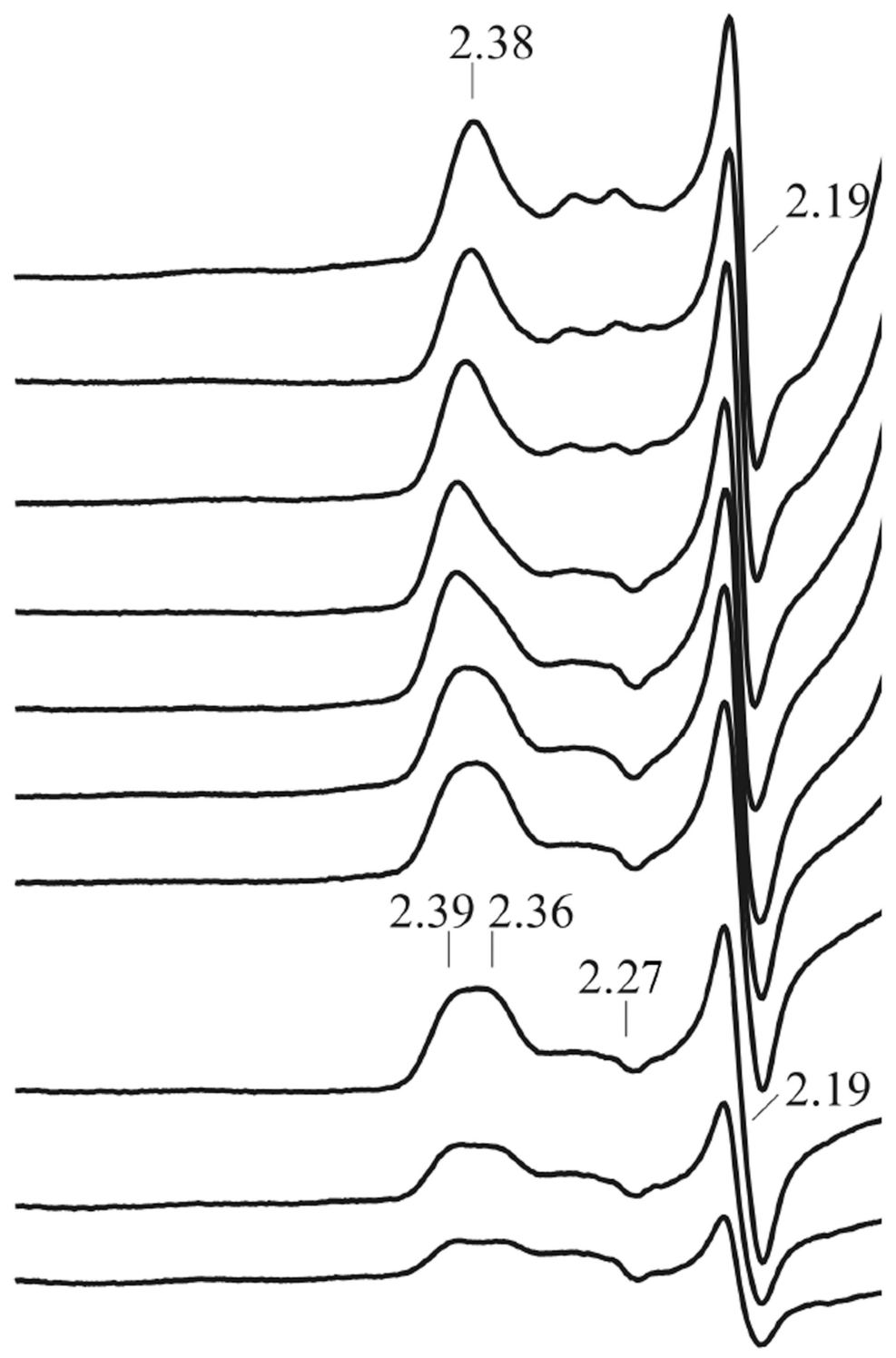

$$
\mathrm{T}_{\mathrm{an}}(\mathrm{K})
$$

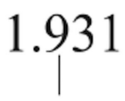

FIELD, G

Figure 2.

$\mathrm{X}$-band EPR spectra of cryoreduced oxy-Fe(II)-HO2 $2_{s o l}$ annealed at indicated temperatures. Instrument settings: temperature, $28 \mathrm{~K}$; field modulation, $100 \mathrm{kHz}$; modulation amplitude, $10 \mathrm{G}$; microwave power, $10 \mathrm{~mW}$; microwave frequency, $9.362 \mathrm{GHz}$. 

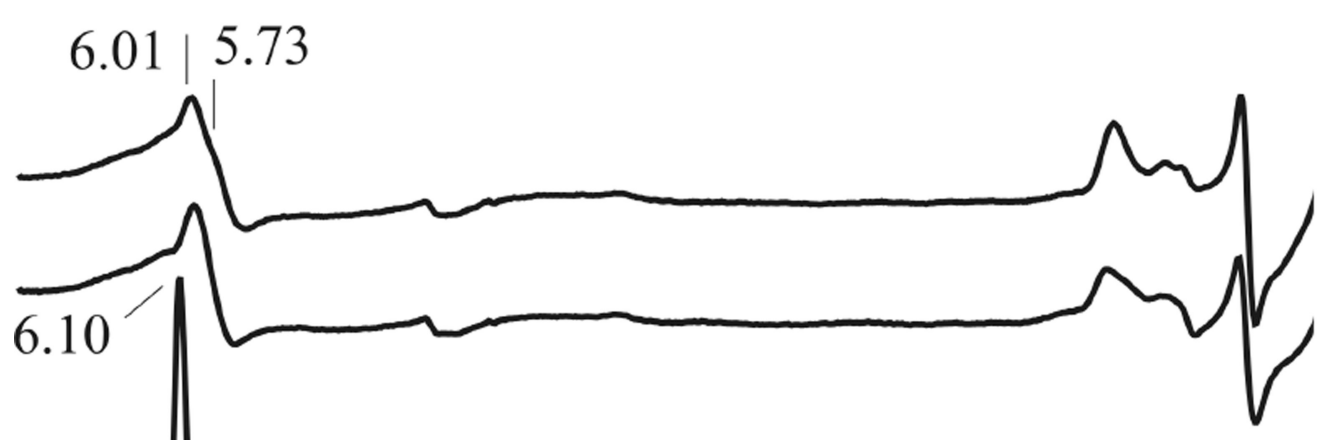

\section{Fe(III)hydroxyheme}
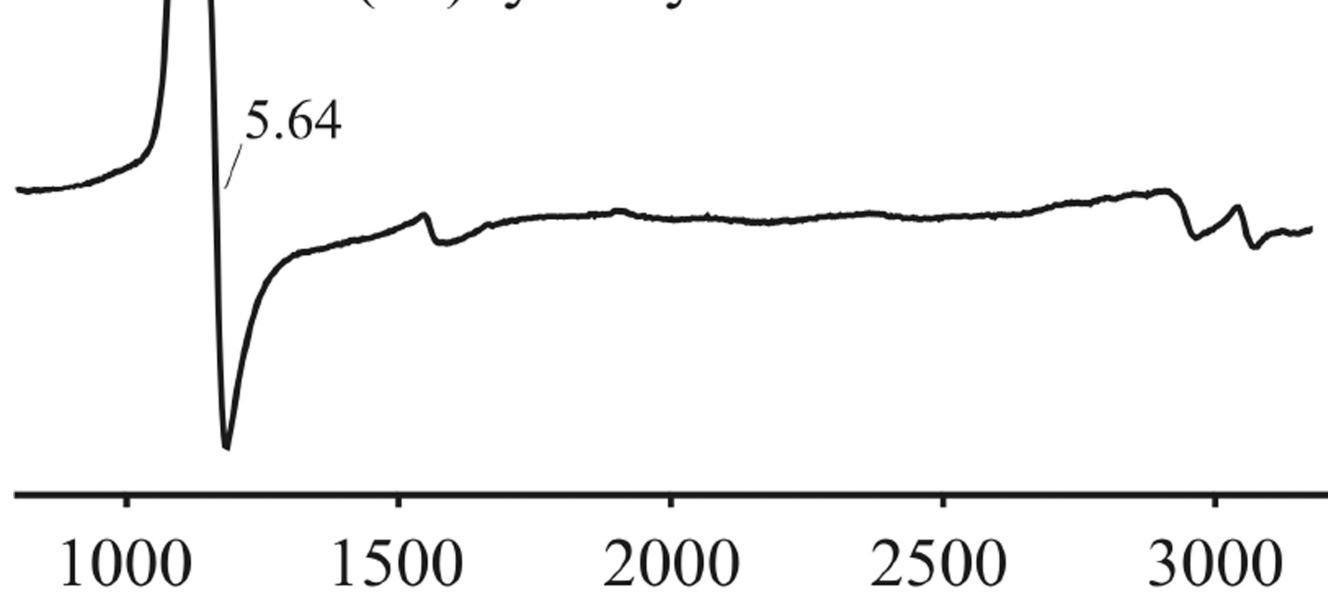

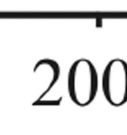

\section{FIELD, G}

\section{Figure 3.}

X-band EPR spectra of cryoreduced oxy-Fe(II)-HO2 $2_{\text {sol }}$ annealed at indicated temperatures. Instrument settings: temperature, $9 \mathrm{~K}$; modulation amplitude, $10 \mathrm{G}$; field modulation, 100 $\mathrm{kHz}$; Microwave power, $2 \mathrm{~mW}$; microwave frequency, $9.362 \mathrm{GHz}$.

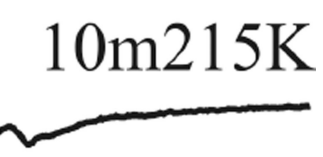




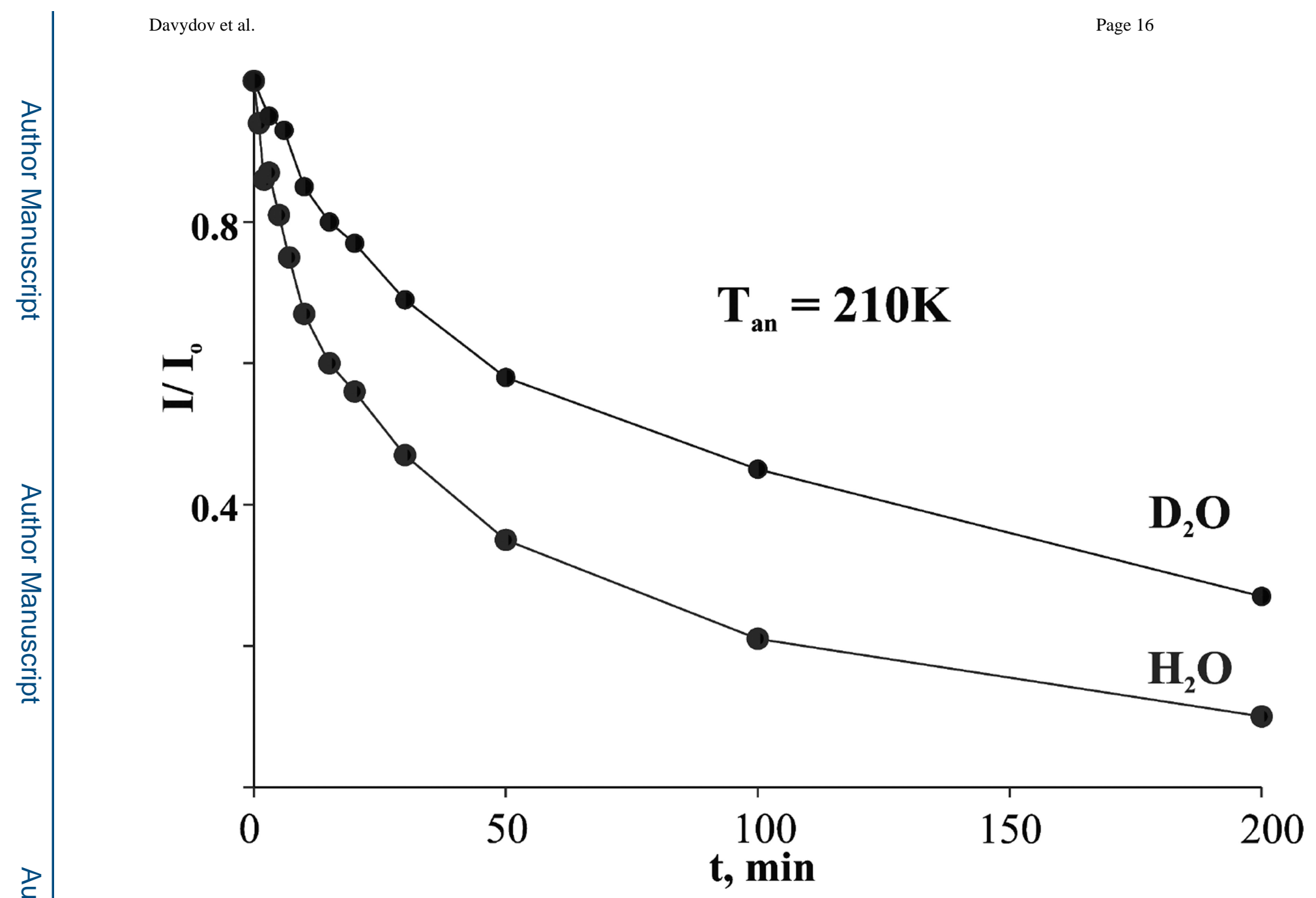

Figure 4.

Kinetics of the decay of the hydroperoxy intermediate of $\mathrm{HO}_{\text {sol }}$ in $50 \%$ glycerol $/ \mathrm{H}_{2} \mathrm{O}$ buffer, $\mathrm{pH} 7.4$, and in $\mathrm{d} 3$-glycerol/ $\mathrm{D}_{2} \mathrm{O}$ buffer $(\mathrm{pH} 7.0)$ at $210 \mathrm{~K}$. 


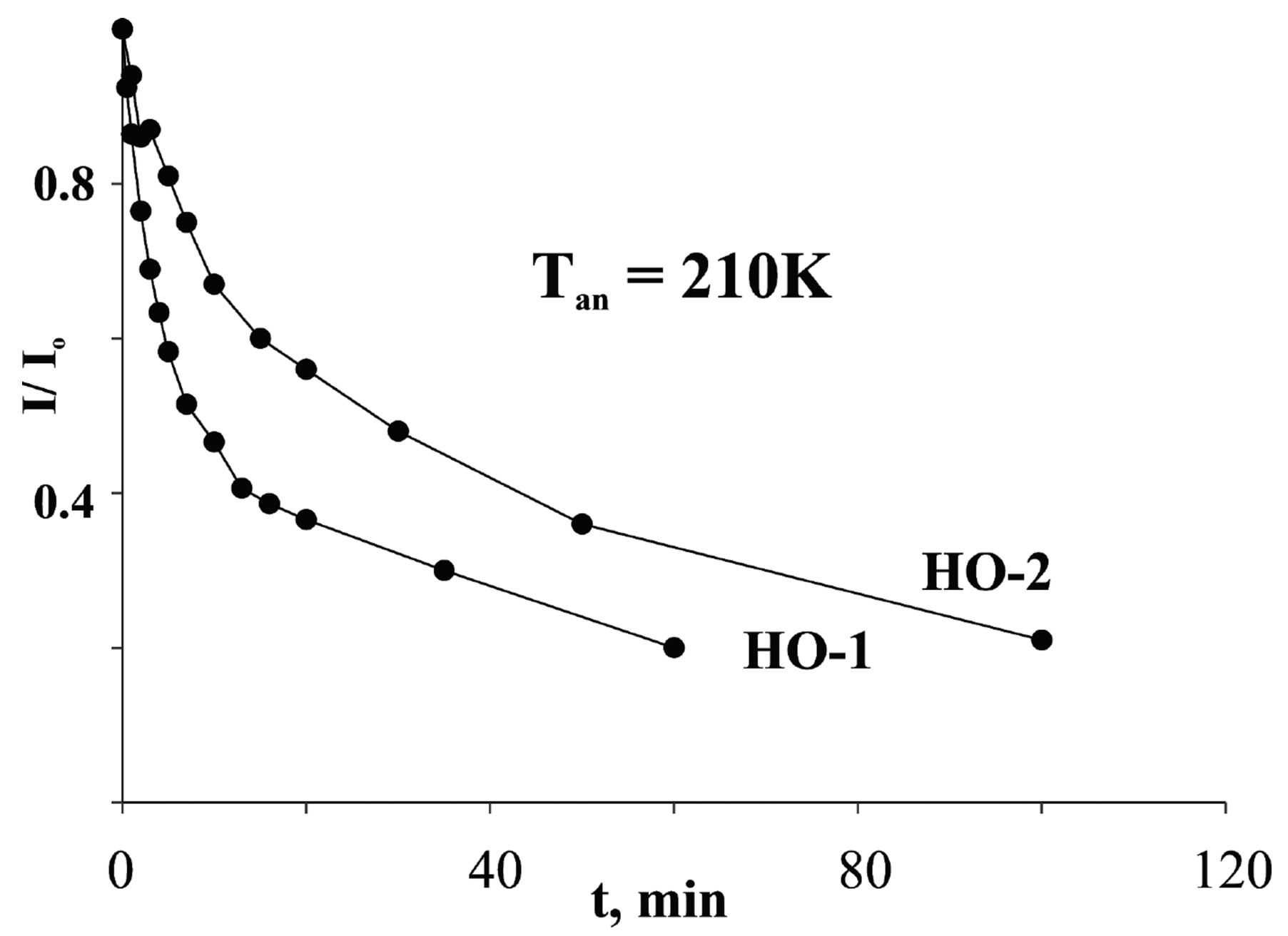

Figure 5.

Kinetics of the decay of the hydroperoxy intermediates of $\mathrm{HO} 1$ and of $\mathrm{HO} 2_{\text {sol }}$ in $50 \%$ glycerol/ buffer, $\mathrm{pH} 7.4$, at $210 \mathrm{~K}$. 